\title{
Ecological status assessment in the lower Eo estuary (Spain). The challenge of habitat heterogeneity integration: A benthic perspective
}

\author{
L. de Paz ${ }^{\mathrm{a}, *}$, J. Patrício ${ }^{\mathrm{b}}$, J.C. Marques ${ }^{\mathrm{b}}$, A. Borja ${ }^{\mathrm{c}}$, A.J. Laborda ${ }^{\mathrm{a}}$ \\ ${ }^{a}$ Department of Biodiversity and Environmental Management, Zoology Area, University of Leon, Campus de Vegazana, 24125 León, Spain \\ ${ }^{\mathrm{b}}$ Institute of Marine Research (IMAR), a/c Department of Zoology, Faculty of Sciences and Technology, University of Coimbra, 3004-517 Coimbra, Portugal \\ ' AZTI-Tecnalia, Marine Research Division, Herrera kaia, Portualdea, z/g, 20110 Pasaia, Spain
}

\section{A R T I C L E I N F O}

\section{Keywords:}

Water Framework Directive

Transitional waters

M-AMBI

Ecological status

Eo estuary

Spain

\begin{abstract}
A B S T R A C T
The implementation of the European Water Framework Directive (WFD) requires evaluation of the ecological status (ES) of benthic communities in coastal and transitional water systems, and the intercalibration of assessment methodologies therefore becomes a research challenge. Our aim was to test the suitability of applying the M-AMBI index to assess the status of the Eo estuary (northern coast of Spain). Our results showed that M-AMBI was influenced by the natural variability of benthic communities, and presented an apparent dependence on habitat characteristics. Consequently, the definition of homogeneous areas in transitional water systems should be based on the salinity gradient combined with other factors. To achieve an accurate ES assessment, habitat-specific reference conditions should then be defined prior to the application of M-AMBI; this necessitates dividing an estuary into several sections, which may be classified as different ESs. From this perspective, a novel approach to integrate habitat heterogeneity in a global ES assessment was tested.
\end{abstract}

() 2008 Elsevier Ltd. All rights reserved.

\section{Introduction}

The European Water Framework Directive (WFD; EC, 2000) establishes a framework for the protection and improvement of all European surface and ground waters, with the final objective being to achieve at least "Good" Ecological Status (ES) for all waters by 2015 . The WFD implementation requires the division of surface waters into water bodies, which will then be monitored in order to establish their ESs. This is carried out by assessing the status of hydro-morphological, physicochemical and biological quality elements, through the comparison of data acquired from monitoring networks with reference conditions representing "the period without anthropogenic influence", or the best achievable conditions (for details, see Borja, 2005).

Benthic invertebrate fauna constitute one of the biological quality elements to be considered in surface water bodies, which include coastal and transitional water systems. The main parameters to be addressed by a benthic invertebrate classification scheme are the level of diversity and abundance of invertebrate taxa', and the proportion of 'disturbance sensitive taxa'. In recent years, numerous benthic indices have been developed or adapted to fulfil the WFD requirements, following the criteria of disturbance sensitive taxa (e.g., Borja et al., 2000; Simboura and Zenetos,

\footnotetext{
* Corresponding author. Tel.: +34 987291515; fax: +34 987291855

E-mail address: lpazl@unileon.es (L. de Paz).
}

2002; Rosenberg et al., 2004; Dauvin and Ruellet, 2007). These indices have been tested and compared elsewhere, alone or together with other community structural parameters (e.g., Salas et al., 2004; Reiss and Kröncke, 2005; Quintino et al., 2006; Blanchet et al., 2008). However, the development and use of integrative metrics that combine disturbance sensitive taxa and diversity indices in order to fulfil the WFD requirements is less extensive. For this reason, Borja et al. (2004a) and Muxika et al. (2007) proposed a new multivariate index, named M-AMBI, which integrates different metrics (species abundance, Shannon diversity index and AZTI's Marine Biotic Index (AMBI) (Borja et al., 2000)). This benthic tool constitutes the Spanish proposal to assess the ES of benthic assemblages within the North Atlantic Eco-region, which has been intercalibrated with other European methodologies (although only for coastal water bodies) (Borja et al., 2007), and also with other methods utilised in the transitional waters of the USA (Borja et al., 2008). However, only small advances have been made for European transitional waters. Therefore, the intercalibration of benthic methodologies in transitional waters will be a major research challenge in the near future (Borja, 2005; Dauvin, 2007).

The M-AMBI application to assess the ES in transitional water bodies should be carefully considered due to the ontogenic natural characteristics of this kind of system. The similarity between the features of organisms and assemblages in natural estuaries compared to anthropogenically stressed estuarine areas makes it difficult to distinguish the effects of human-induced stress in estuaries. 
This was termed as the Estuarine Quality Paradox (Elliott and Quitino, 2007; Dauvin, 2007), and must be taken seriously when establishing the reference conditions for this type of water body (Borja et al., 2003).

Prior to the establishment of reference conditions, it is necessary to assign each water body to a specific typology, since reference conditions should remain type-specific (Vincent et al., 2002). However, transitional waters, which are characterised by highly variable physicochemical and hydro-morphological conditions, typically result in a mosaic of different habitats (Escavarage et al., 2004), and a single water body can show very different natural conditions. Therefore, the low salinity areas of the inner estuary naturally support less diverse faunal assemblages compared to the higher salinity areas of the estuarine mouth. If only one set of reference values is used for each type, i.e., the same reference conditions are used for downstream and upstream areas of an estuary, the naturally impoverished biological communities of the inner estuary would always be classified as having a worse ES than the estuary mouth areas, independent of the existence of any potential impacts. Therefore, in transitional waters, specific reference conditions for each stretch of a water body should be considered (Bald et al., 2005; Muxika et al., 2007; Teixeira et al., 2007; Borja et al., 2008).

It is widely accepted that salinity is one of the main factors influencing species distributions in estuaries (McLusky and Elliott, 2004). Consequently, in the Basque Country (Spain), in order to reflect 'water bodies' specific hydrographical properties, estuaries were split into different water sections, using salinity gradient as the characterisation factor and the Venice Symposium system for class definitions (Bald et al., 2005; Muxika et al., 2007). This approach is also being used to establish quantitative reference conditions for transitional waters in the United Kingdom and in the Republic of Ireland (Prior et al., 2004). However, in addition to salinity, other factors such as sediment grain size, organic matter content, dissolved oxygen, depth, hydrodynamic conditions and vegetation cover may also control species distributions in estuaries (Ysebaert et al., 2003; Blanchet et al., 2004). Therefore, in some estuarine systems, assigning benthic reference conditions to sections based exclusively on salinity may be difficult and potentially inaccurate (Teixeira et al., 2008).

The importance of establishing habitat-specific reference conditions within transitional water bodies in final ecological assessments has been suggested by several authors in order to avoid misclassification (e.g., Bald et al., 2005; Muxika et al., 2007; Borja et al., 2007; Blanchet et al., 2008; Teixeira et al., 2008). However, following the WFD principles, such a differentiation would necessitate dividing the estuary into several water bodies. This may cause difficulties in managing small estuaries (Borja et al., 2004a; Ferreira et al., 2006). For this reason, the habitat level assessment needs to be integrated in a large-scale estimation of the ecological status of the entire water body (Borja et al., 2005; Puente et al., 2008).

The Eo estuary is a shallow system, on the northern coast of Spain, within the North Atlantic Eco-region (Fig. 1). In the last fifteen years, three extensive surveys have been carried out in the outer part of this estuary to examine long-term changes in its macrobenthic communities, relating to such changes as the increase in human pressure observed during this period (de Paz et al., in press). The objective of this work, using data sets from the Eo estuary, was to test the suitability of methodological procedures proposed in the Basque Country for benthic assessment within the scope of the WFD (Bald et al., 2005; Muxika et al., 2007; Borja et al., 2007). This system belongs to the same biogeographical region and presents similar hydrological and geomorphological features as estuaries in the Basque Country (Fig. 1) in which the reference conditions used in this contribution were developed.
The sampling strategy focused on habitat variability (characteristics, location and temporal modification). Consequently, our data set allowed the development of a novel approach to integrating habitat heterogeneity (single station or habitat type) in the global ES assessment of the outer Eo estuary, thus contributing to the new intercalibration phase for transitional waters.

\section{Materials and methods}

\subsection{Study area}

The Eo estuary, located on the northern Cantabrian coast of Spain $\left(43^{\circ} 28^{\prime}, 33^{\prime} \mathrm{N} ; 7^{\circ} 00^{\prime}, 03^{\prime} \mathrm{W}\right)$, constitutes a shallow mesotidal system (tidal range varies from $1.20 \mathrm{~m}$ during neap tides to $4.80 \mathrm{~m}$ during spring tides (Encinar and Rodríguez, 1983)) (Fig. 1) with a total area of $9.6 \mathrm{~km}^{2}, 10 \mathrm{~km}$ in length, and an average width of $800 \mathrm{~m}$. Water depth varies between 2 and $7 \mathrm{~m}$. According to the WFD typology established for the Basque Country (Borja et al., 2004a), the Eo estuary may be assigned to type TW II. This type includes mesotidal (tidal range 1-3 m) polyhaline-euhaline estuaries with extensive intertidal areas and permanent stratification.

The sampling area (Fig. 1) in the lower part of the estuary is comprised of two sectors: (a) a sheltered inlet, the Linera inlet, located on the western side of the estuary; and (b) a sandy bare bottom area, consisting of sand banks, located in the main channel. The Linera inlet represents a flat area of $1.5 \mathrm{~km}^{2}$, mainly covered by Zostera noltii and Zostera marina seagrass beds. Z. noltii occurred on muddy areas located at higher tidal levels in the inner part of Linera inlet, while a mixed meadow of both species could be found in muddy-sand habitats from lower tidal levels near the mouth of the inlet. Over time, both the shape and the area of the sand banks have been continuously changing and increasing in size (Encinar and Rodríguez, 1983). As is the case for other systems along the northern coast of Spain, a gradual process of being filled up by marine and estuarine deposits has been taking place at the Eo estuary (Currás and Mora, 1991).

The major human pressure at the Eo estuary is shellfish farming, which began in the 1970s with Ostrea edulis aquaculture. However, after the catastrophic introduction of a parasite (Bonamia ostreae), the culture of the species collapsed in 1978. In the late 1980s and early 1990s, shellfish farming in the estuary got a new stimulus following the introduction of the Pacific oyster (Crassostrea gigas) and the Manila clam (Ruditapes philippinarum) (Cigarría et al., 1995), which are cultivated in culture bags placed onto racks. Farming areas are located at the Linera inlet (Fig. 1) (occupying 37\% of the total inlet area since 2000) and at the Fontela banks (where an area of 30 ha was established by the end of 2005). Both culture zones are situated on intertidal Zostera seagrass beds. The increase in this activity is probably the main reason for eutrophication of the area; this has been observed in the estuary since 2000 (e.g., a considerable development of green macroalgae) (de Paz et al., 2008). Other anthropogenic pressures in the estuary are related to hydrodynamic changes caused by harbour construction, mainly from 1994 (Fig. 1), and by regular dredging for maintenance of the shipping channels. In fact, the Eo catchment area is poorly urbanized, and does not support intensive agriculture or significant industrial activities. The only industry located in the estuary is a shipyard (Fig. 1), which started activities in 1965.

\subsection{Sampling and laboratory procedure}

An extensive survey was carried out in 1990 to determine the different habitats present in the Eo estuary (de Paz et al., 2008 and references therein). Three different habitat types were identified based on sediment granulometry, organic matter content, sea- 


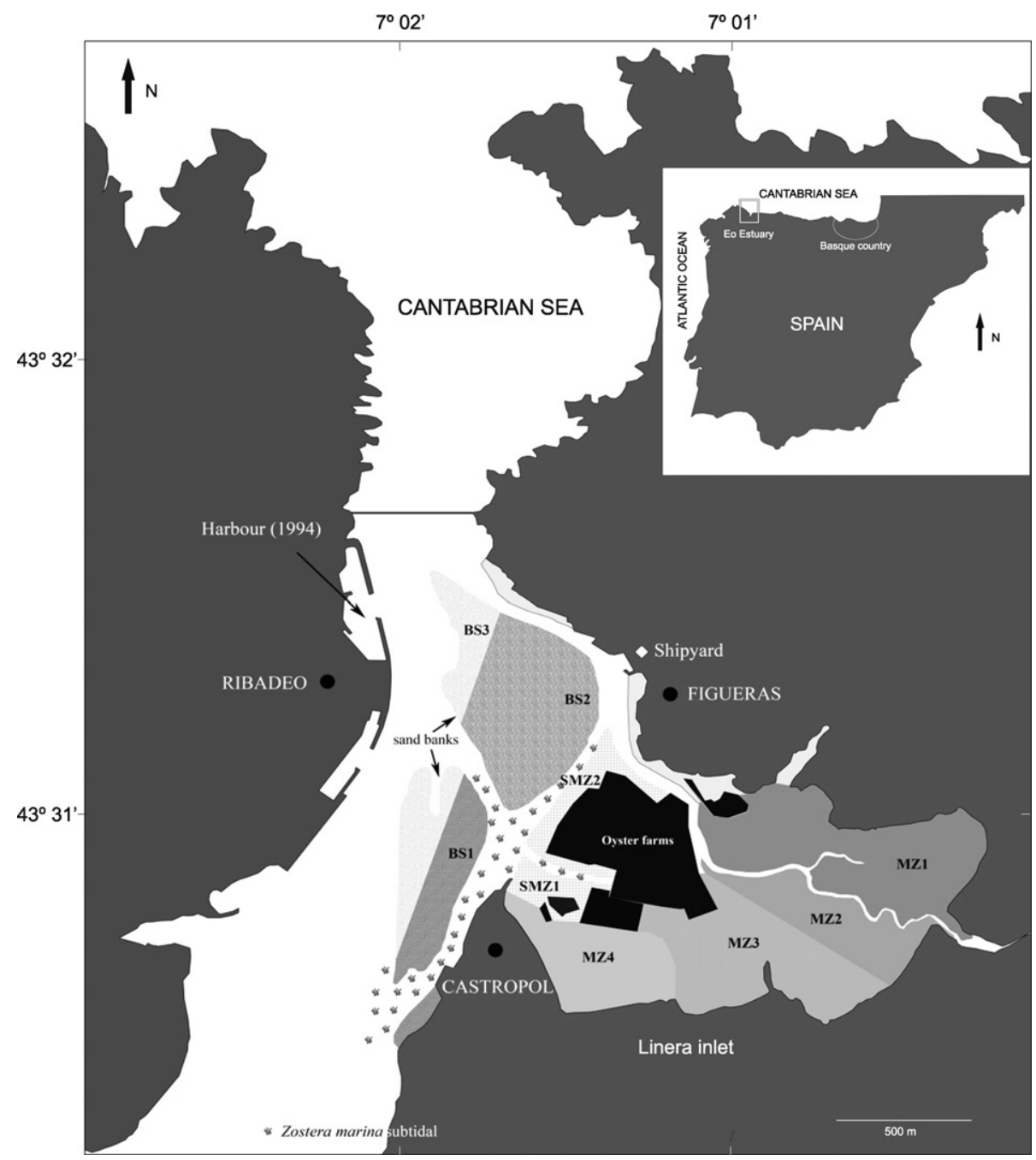

Fig. 1. Eo estuary (northern Cantabric coast of Spain): location of the sampling stations and habitat types.

grass cover and macrobenthic community distribution (Fig. 1): (a) bare sand area, corresponding to sand banks and beaches (BS zone); (b) mudflats covered by $Z$. noltii, located in the inner part of the Linera inlet ( $\mathrm{MZ}$ zone); and (c) mixed meadows of $Z$. noltii and $Z$. marina, on sandy and sandy-mud sediments, located in the outer part of the Linera inlet (SMZ zone).

Based on macrobenthic communities and physicochemical parameters, different zones were recognised within each habitat and characterised in 1990. Therefore, in 2000 and 2005, the sampling stations were selected to represent all habitat variability present in the study area. A total of nine stations overlapped the points sampled in 1990 (Fig. 1): three stations on the bare sand habitat (BS1, BS2 and BS3), two stations on the Z. noltii-Z. marina mixed meadows (SMZ1, SMZ2), and four stations on the mudflats covered by Z. noltii (MZ1, MZ2, MZ3, MZ4). These habitats were distributed almost as a continuum along the study area, from the inner sections of the Linera inlet to the outer part of the main channel (Fig. 1), and consequently transition areas were recognised between them. Thus, station MZ4 was located on the transition area between the mudflats covered by $Z$. noltii and the $Z$. noltii-Z. marina mixed meadows, and station BS1 was located on the transition area between this last habitat and the bare sand area, which was limited by a $Z$. marina subtidal seagrass bed (de Paz et al., 2008).

In 1990, 2000 and 2005, samples were collected during low spring tides, in February (winter), May (spring), August (summer) and October (autumn). However, since the references values used in this study were derived from winter samples (Muxika et al., 2007), only winter samples were used to assess the ecological status in order to reduce seasonal variability, which may have affected the results of comparisons.

In 1990, the minimum sampling area for the study zone was determined, and a single sample $\left(0.16 \mathrm{~m}^{2}\right.$ and $0.35 \mathrm{~m}$ depth $)$ was collected at each site using a spade. No true replicates were done, and for that reason the sampled area was reduced and the number of replicates increased in the next surveys (2000 and 2005). In 2000 and 2005 , eight replicates $\left(0.0123 \mathrm{~m}^{2}\right.$ and $0.2 \mathrm{~m}$ depth) were taken at each sampling station using a manual corer. A test demonstrated that results obtained by these two different sampling approaches were comparable, since differences with regard to the number of species and their abundances were not significant (de Paz et al., 2008). Samples were sieved in the field through a $0.5 \mathrm{~mm}$ mesh, and preserved in $4 \%$ buffered formalin. After sorting, benthic macroinvertebrates were identified to the species level, counted and stocked in $70 \%$ alcohol.

Bottom salinity values were seasonally recorded in situ at each of the nine sampling stations, at low tide. Sediment samples were also taken seasonally at each station using a spade (in 1990), or a manual corer (in 2000 and 2005). The sediment organic matter content was determined by loss on ignition $\left(24 \mathrm{~h}\right.$ at $\left.450{ }^{\circ} \mathrm{C}\right)$. Sediment grain size was determined using the standard mechanic 
sieved procedure (Buchanan, 1984). According to the Wentworth scale, seven granulometric fractions were taken into account: graves $(\emptyset>2 \mathrm{~mm})$, very coarse sand $(2 \mathrm{~mm}>\emptyset>1 \mathrm{~mm})$, coarse sand $(1 \mathrm{~mm}>\varnothing>0.5 \mathrm{~mm})$, medium sand $(0.500 \mathrm{~mm}>$ $\emptyset>0.250 \mathrm{~mm})$, fine sand $(0.250 \mathrm{~mm}>\varnothing>0.125 \mathrm{~mm})$, very fine sand $(0.125 \mathrm{~mm}>\varnothing>0.062 \mathrm{~mm})$ and silt $(\varnothing<0.062 \mathrm{~mm})$. Grain composition was expressed in percentage of total sample weight.

\subsection{Data analysis}

Each station was assigned to a salinity category, according to the Venice Symposium (Anon., 1959) (oligohaline: 0.5-5; mesohaline: 5-18; polyhaline: $18-30$ and euhaline: >30) by means of a cluster analysis (CA), which was based upon the maxima, minima, median and standard deviation of salinity data for all seasons, from 1990, 2000 and 2005. Data were standardised by subtracting the mean value and dividing by the standard deviation to achieve a normal distribution. The Euclidean distance between groups, a dissimilarity measure, and the Ward's minimum variance method were used (see Bald et al., 2005 and references therein).

The ecological quality ratio (EQR) of each sampling station was calculated using the multivariate approach called M-AMBI proposed by Borja et al. (2004a) and Muxika et al. (2007). This multivariate index is composed of three different metrics: number of species $(S)$, Shannon diversity index $\left(H^{\prime}\right)$ and the AMBI index (Borja et al., 2000). The method is based on a factor analysis including two virtual samples, which represent 'High' and 'Bad' ecological quality status. The EQR (M-AMBI value) of each sampling station is determined by calculating the Euclidean distance between the projection of the station to the line connecting both reference stations, and the 'Bad' reference station (see Bald et al., 2005). 'High' and 'Bad' specific reference values for the structural parameters were selected according to those proposed by Muxika et al. (2007). Once the M-AMBI is calculated, an ES is assigned according to the class boundaries defined specifically for Spain (Borja et al., 2007). These analyses were carried out using the AMBI software (Borja and Muxika, 2005 and http://www.azti.es).

The statistical significance of differences in M-AMBI values among sampling years was further examined using one-way ANOVA. Prior to the analysis, Levene's test for homogeneity of variance was used, as well as the Kolmorogov-Smirnov test for normality. Tukey's Honestly Significant Difference post hoc test was used following a significant ANOVA result $(p<0.05)$. The purpose was to compare the M-AMBI index values to distinguish between three different environmental scenarios: (a) prior to intensive oyster cultivation (1990), (b) during a new extensive oyster rack installation (2000), and (c) after some years of shellfish farming (2005). To assess the possible influence of natural habitat characteristics in establishing ES according to the M-AMBI method, one-way ANOVA was applied to test if differences observed in M-AMBI values among habitats were statistically significant. Additionally, Spearman's correlations between M-AMBI values and sediment parameters (grain size fractions and organic matter content) were applied. All statistical analyses were performed using SPSS software.

\subsection{Final integrative ES assessment of lower part of the Eo estuary}

The EQR of each habitat was estimated as a mean M-AMBI value calculated for all the stations in that habitat. To assess the final ES of the lower part of the Eo estuary we accounted for the relative importance of the habitat area to the area of the entire water body. Only the intertidal area (approximately 65\% of the total) was taken into account when calculating the area of the lower part of the estuary. Since macrobenthic community data from the farming area after the rack assessment was not available, these data were not taken into account. The area occupied by the different habitats during the different years was calculated using GPS field data and through the analysis of aerial and satellite photographs (with OziExplorer GPS mapping software and ArcGIS software). The lower estuary final ES was calculated for each of the three years (1990, 2000 and 2005).

\section{Results}

\subsection{Salinity category and reference conditions}

All stations could be clearly assigned to a euhaline salinity class in accordance with the Venice symposium (Fig. 2). Salinity values recorded in the mudflats covered by the $Z$. noltii seagrass corresponded to the euhaline estuarine salinity class, while at stations in the $Z$. noltii-Z. marina mixed meadows and at the sand banks, values were assigned to a euhaline sea salinity class. Consequently, we selected the reference conditions established by Borja et al. (2005) and Muxika et al. (2007) for euhaline estuarine areas

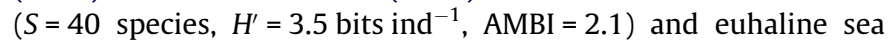
areas $\left(S=42\right.$ species, $H^{\prime}=4$ bits ind $\left.^{-1}, \mathrm{AMBI}=1\right)$.

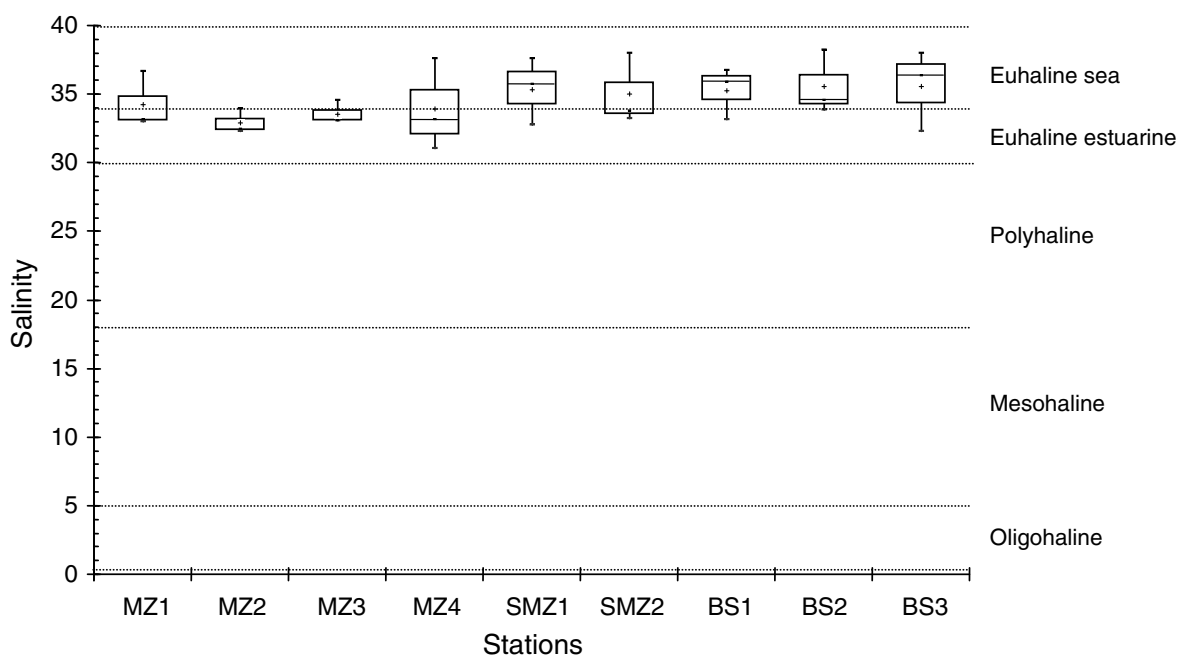

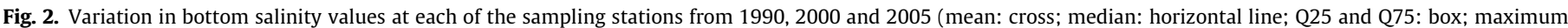

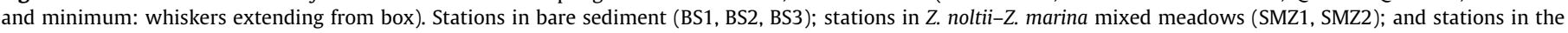
mudflats covered by $Z$. noltii (MZ1, MZ2, MZ3, MZ4). 


\subsection{Ecological quality status assessment}

The sample distribution in the three-dimensional space defined by the factor analysis, corresponding to 1990, 2000 and 2005, is shown in Fig. 3. Independent of year, the poorest EQR values were found at stations on the mudflats covered by $Z$. noltii, and the highest values at stations in the $Z$. marina- $Z$. noltii mixed meadow, while stations on the bare sand area had intermediate values. Through a one-way ANOVA we verified, within each sampling period, that the M-AMBI values differed significantly between the three habitats (Table 1). Both in 1990 and 2000, a Tukey's test showed that M-AMBI values were significantly lower in the stations on mudflats covered by $Z$. noltii than in those located on the $Z$. marina-Z. noltii mixed meadows (Table 1 ). However, although M-AMBI values were lower in the bare sand area than in the Z. marina-Z. noltii mixed meadows, differences were not significant. On the other hand, in 2005 , despite the fact that the stations on the $Z$. marina- $Z$. noltii mixed meadows also showed the highest M-AMBI values, differences found from habitat pairwise comparisons were not significant (Table 1).
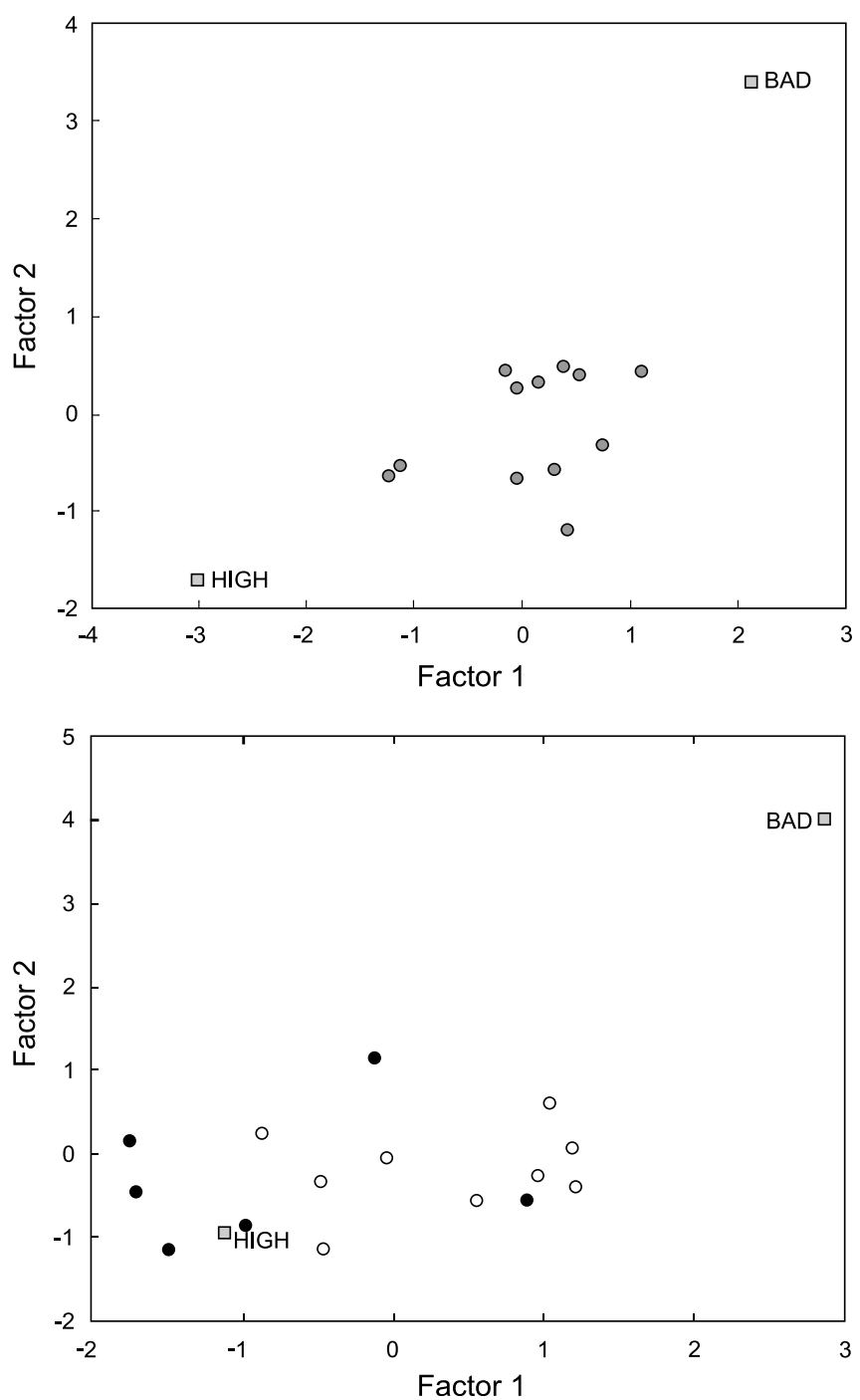

Fig. 3. Sample distribution in three-dimensional space defined by factor analysis, corresponding to 1990, 2000 and 2005. (A) Euhaline estuarine and (B) euhaline sea. Grey circles: stations in the mudflats covered by Z. noltii (MZ1, MZ2, MZ3, MZ4); white circles: stations in bare sediment (BS1, BS2, BS3); and black circles: stations in $Z$. noltii-Z. marina mixed meadows (SMZ1, SMZ2).
Table 1

Comparison of M-AMBI index values at each habitat in every sampling year

\begin{tabular}{|c|c|c|c|c|c|}
\hline & $n$ & Mean & $F$ & $p$ & Significant Tukey post hoc test \\
\hline 1990 & 9 & 0.154 & 7.324 & $0.025^{*}$ & $\begin{array}{l}\mathrm{MZ}<\mathrm{SMZ}^{*} \\
\mathrm{MZ}<\mathrm{BS}^{\mathrm{ns}} \\
\mathrm{BS}<\mathrm{SMZ}^{\mathrm{ns}}\end{array}$ \\
\hline 2000 & 9 & 0.097 & 7.204 & $0.025^{*}$ & $\begin{array}{l}\mathrm{MZ}<\mathrm{SMZ}^{*} \\
\mathrm{MZ}<\mathrm{BS}^{\mathrm{ns}} \\
\mathrm{BS}<\mathrm{SMZ}^{\mathrm{ns}}\end{array}$ \\
\hline 2005 & 9 & 0.116 & 6.524 & $0.031^{*}$ & $\begin{array}{l}\mathrm{MZ}<\mathrm{SMZ}^{\mathrm{ns}} \\
\mathrm{MZ}<\mathrm{BS}^{\mathrm{ns}} \\
\mathrm{BS}<\mathrm{SMZ}^{\mathrm{ns}}\end{array}$ \\
\hline
\end{tabular}

Values from ANOVA with Tukey's pairwise comparison test.

${ }^{\mathrm{ns}} p>0.05 ;{ }^{*} p<0.05$.

With the exception of coarse sand and sedimentary organic matter, all grain fractions showed strong Spearman correlations with M-AMBI, as well as amongst themselves. Therefore, these variables appear to influence the ES in the different habitats present in the lower part of the Eo estuary. There was a significant negative linear correlation between M-AMBI values and silt-clay $(r=-0.512 ; p<0.01)$ and very fine sand $(r=-0.656 ; p<0.05)$; and a positive correlation with the proportion of fine $(r=0.631$; $p<0.05)$ and medium grained sand $(r=0.693 ; p<0.05)$.

Temporal trends in EQR values and the corresponding ES obtained by applying the M-AMBI method are shown in Fig. 4. Despite the general quality degradation detected at all stations since 1990 , the ES at stations located in the $Z$. noltii- $Z$. marina mixed meadow, at the bare sand area, and at the transitional mudflat (MZ4) was classified as 'High' or 'Good' during the whole study period (Fig. 4A). On the other hand, the ES was classified as 'Moderate' or 'Poor' at stations MZ2 in all years, at MZ1 in 1990 and 2005, and at MZ3 in 2000 and 2005, and therefore did not comply with the WFD objective. Taking into account the mean values per habitat (Fig. 4B), the habitats also showed ecological quality degradation from 1990 to 2000, and a slight recovery from 2000 to 2005 (higher EQR at SMZ, followed by BS and then by MZ). Nevertheless, differences in the mean M-AMBI values between years were not significant $(F=0.467 ; p>0.05)$.

\subsection{Euhaline final integrative ES assessment}

The estuarine intertidal area increased over the study period, from 193 ha in 1990 to 212 ha in 2005 . This was mainly caused by an increase in sand deposition, and thus the enlargement of the bare sand area (from 53 ha in 1990 to 70 ha in 2005). However, we observed an important reduction in the extension of the Zostera seagrass beds (from 140 ha in 1990 to 102 ha in 2005), namely for the mixed Z. noltii-Z. marina meadow (from 40 ha in 1990 to 8 ha in 2005). This is actually the area where most of the culture racks have been installed, and before their placement, seagrass was removed, leaving the sediments beneath the farms without vegetation.

The final EQR values for the euhaline stretch and its corresponding ES in each year were calculated. Although in all years the Eo estuary euhaline stretch was classified as 'Good' $\left(\mathrm{EQR}_{90}=0.705\right.$; $\mathrm{EQR}_{00}=0.550$ and $\mathrm{EQR}_{05}=0.609$ ), deterioration in the system's ecological quality has been observed since 1990, and especially in 2000. Results also suggest that a slight recovery occurred in 2005 compared to the situation in 2000 .

\section{Discussion}

Temporal changes regarding anthropogenic pressures in the Eo estuary have been detected with the M-AMBI index at each of the three habitats, and results were consistent with the existing 

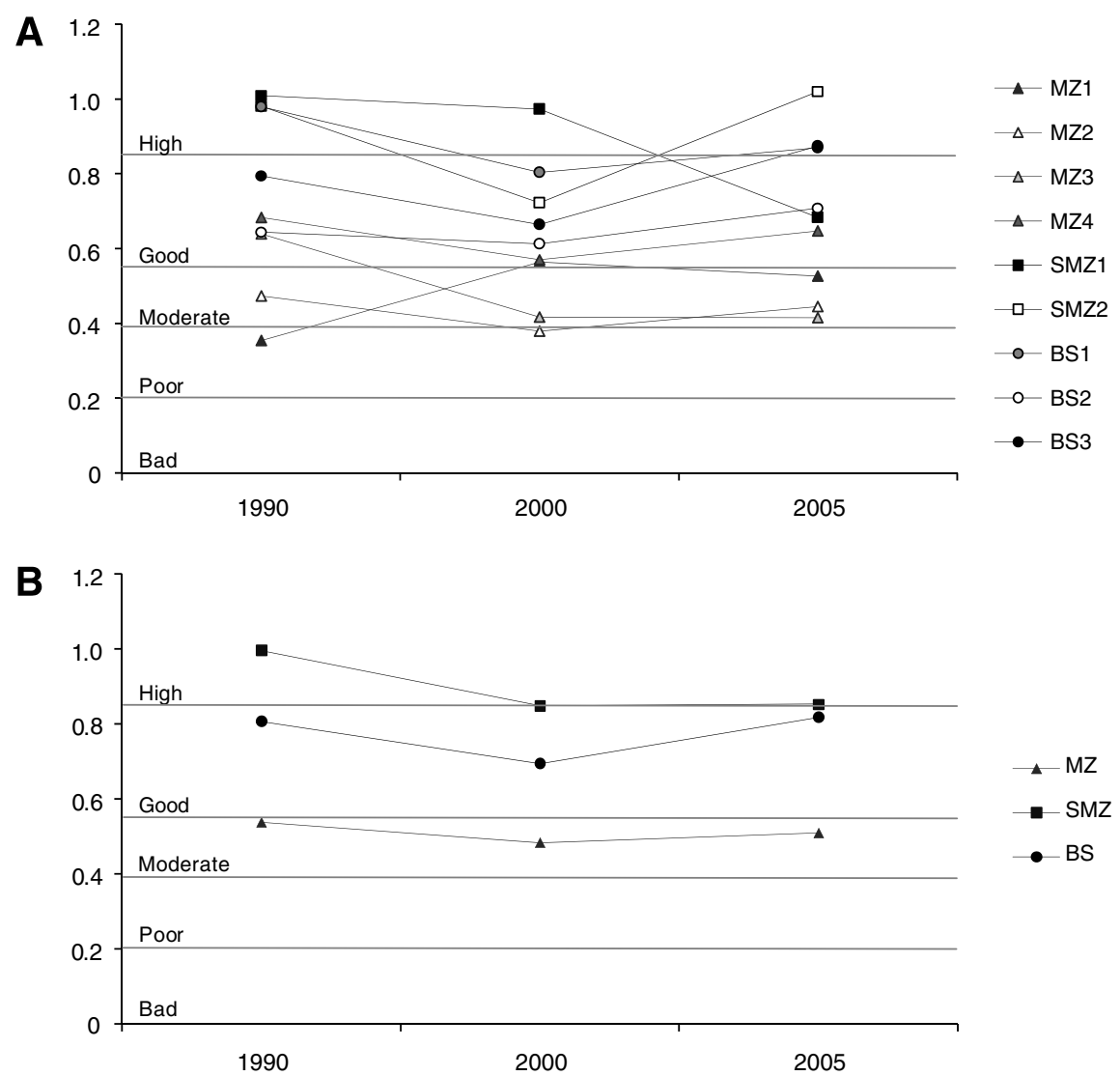

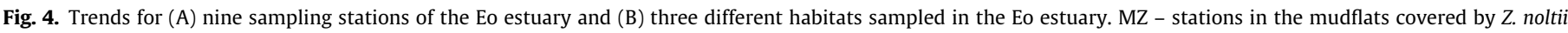
(MZ1, MZ2, MZ3, MZ4). BS - stations in bare sediment (BS1, BS2, BS3). SMZ - stations in Z. noltii-Z. marina mixed meadows (SMZ1, SMZ2).

knowledge of the system alteration though time (de Paz et al., in press). The lowest pressure from shellfish farming was in 1990. Since then, anthropogenic pressure resulting from bivalve farming in the area has been increasing, and this activity probably became the major driving force behind the organic enrichment observed at the Linera inlet (de Paz et al., 2008). This may explain the degradation of the benthic ES observed in habitats located at the Linera inlet from 1990 to 2000. On the other hand, the degradation of macrobenthic ecological quality observed at the bare sand area may be related to an increase in physical disturbance, as the Eo estuary, like other systems along the northern coast of Spain, has been going through a gradual process of being filled up by marine and estuarine deposits (Currás and Mora, 1991). Furthermore, sediment deposition became more rapid after the construction of a new harbour in the western part of the Eo estuary in 1994, and an increase of 17 ha in the sand banks took place from 1990 to 2005.

However, differences observed between sampling years were not statistically significant, which may be due to the fact that all our sampling stations were located outside the farms (see Fig. 1). In fact, some studies show strong gradients of impact from oyster farms out to a certain distance (Stenton-Dozey et al., 1999; Mirto et al., 2000; Hartstein and Rowden, 2004). Therefore, it is expected that higher impacts, corresponding to lower M-AMBI values, should be detected within the farms. On the other hand, the strong spatial variability across samples may be sufficient to mask small changes in macrobenthic communities over the study period.

It is clear that habitat characteristics had a strong influence in the Eo estuary ES assessment, since the M-AMBI values showed dependence on sediment parameters and on the presence/absence of seagrass beds. For this reason, stations at the mudflats had the poorest ES values, independent of year, while the best ES values were found at the $Z$. noltii-Z. marina meadows over the entire study period.

The AMBI development was based on the relationship between macrofaunal communities and gradients of increasing organic matter input related to either urban effluents or eutrophication processes (Pearson and Rosenberg, 1978; Grall and Glémarec, 1997; Borja et al., 2000). Therefore, in muddy environments (which are common in estuaries) where sediment organic matter is naturally high, this index generally expresses lower quality, despite the absence of impacts (Blanchet et al., 2008; de Paz et al., 2008). As a possible solution to these index limitations, Borja et al. (2003, 2004a) and Muxika et al. (2005) recommended that AMBI should be used together with other structural parameters, such as the M-AMBI index (Muxika et al., 2007). However, community structural parameters, such as species number and the Shannon diversity index are also affected by estuarine natural gradients. It is generally accepted that the presence of seagrass beds enhances diversity and species richness (Edgar et al., 1994; Boström and Bonsdorff, 1997). Conversely, high organic matter content, as is found in muddy environments, may cause a decrease in species richness and an increase in abundance. Therefore, a multivariate index based on a combination of these three parameters (i.e., MAMBI) may also be influenced by natural stressors. Our results show that an increase in the proportion of fine particles in the sediment corresponds to a reduction in M-AMBI values, which is related to an increase in AMBI values and a decrease in diversity and species richness. Consequently, in 1990, despite the smaller anthropogenic impacts as compared to subsequent years, the ES at stations MZ1 and MZ2, located in the mudflat covered by Z. noltii, was classified as "Poor" and "Moderate", respectively. Our re- 
sults therefore show that by using M-AMBI, the natural variability at the Eo estuary influences the ES assessment, which illustrates the problems of distinguishing between natural and human-induced gradients in transitional water systems.

These limitations could be removed by the determination of appropriate type-specific reference conditions, according to the specific natural characteristics of each water body type. The Spanish methodological approach used in this study establishes different reference conditions for each salinity category (Muxika et al., 2007), and is based on the association of benthic communities and saline categories (Borja et al., 2004b; Muxika et al., 2007). However, our results showed that the division of the Eo estuary into smaller homogeneous water bodies based upon salinity gradients is not sufficient to reflect natural benthic gradients.

Salinity is recognised as a very important factor influencing macrobenthic community distribution in estuaries (McLusky and Elliott, 2004). Moreover, the estuarine salinity gradient is often associated with sedimentary changes, from coarse sediment outside the estuaries to fine sediments within them (Elliott and McLusky, 2002). Thus, in most estuarine systems, the oligohaline and polyhaline areas are associated with fine sediments rich in organic matter, and, in contrast, the euhaline areas are often associated with coarser sediments with low organic matter content. This is the pattern found along the main channel of the Eo estuary (Currás, 1990). However, the morphological characteristics of the lower Eo estuary determine the existence of a sediment gradient, which is closely related to the macrobenthic assemblages, but does not match the salinity gradient (de Paz et al., 2008). In fact, the presence of the Linera inlet causes a reduction in current velocity and a concomitant deposition of fine sediment particles, mainly in the inner Linera inlet (Encinar and Rodríguez, 1983; Currás, 1990; de Paz et al., 2008). For this reason, despite the fact that salinity values at the inner and middle parts of the Linera inlet correspond to a euhaline stretch, the macrobenthic assemblages correspond to a Scrobicularia plana-Cerastoderma edule community, sensu Borja et al. (2004b). However, according to Spanish methodology (Muxika et al., 2007), this community may be associated with oligohaline and mesohaline areas of a water body.

Consequently, the Eo estuary case study illustrates that in establishing appropriate reference conditions in estuarine systems, the definition of water bodies as a function of only the salinity gradient may not accurately reflect the entire natural benthic diversity. In some Portuguese systems, Ferreira et al. (2006) proposed another methodology, in which water body delineation was based on physical-chemical aspects such as morphology and salinity, and also on pressure and state indicators. In a similar way, Teixeira et al. (2008) divided the Mondego estuary (Portugal) into six sectors based on salinity, sedimentary parameters and human pressures. These approaches seem to be more suitable for estuaries with complex morphologies, such as the Eo estuary.

On the other hand, from the management point of view, it would be ineffective to split transitional waters systems into too many small water bodies and thereby too many management units (Ferreira et al., 2006; Teixeira et al., 2008; Puente et al., 2008). In small systems, such as the Eo estuary, an effective management plan should include the whole system. For this reason, in the WFD implementation process, it is preferable to develop an integrative methodology to assess the ES of the whole water body (Puente et al., 2008); the present study intends to be a valuable contribution to this process.

The ES of the entire water body should not be established as the mean value of all stations in the system (Borja et al., 2005). If we assume that the habitat level assessment is the most suitable methodology (for benthos) in transitional water systems (Blanchet et al., 2008; Puente et al., 2008), then any integrative assessment should take into account the relative contribution of the different habitats present. In addition, taking into consideration the spatial variation of the relative area of each habitat in the global assessment allows the identification of habitat changes. These perturbations have not yet received much attention despite their importance, particularly in transitional water ecosystems (Dauvin, 2007; Blanchet et al., 2008).

For example, in the Eo estuary, organic enrichment is not the only impact associated with shellfish farming. The destruction of seagrass beds, especially those of the $Z$. noltii and $Z$. marina mixed meadows for the purpose of installing oyster racks, constitutes another important impact in the estuary (de Paz et al., 2008). By considering the relative area of each habitat in the calculation of the total $\mathrm{EQR}$, these changes in the $Z$. marina-Z. noltii mixed meadow influence the final ES, mainly because the macrobenthic communities linked to this habitat have the highest species numbers and diversity values. Despite the lack of data for the culture area after rack installation, it seems that the elimination of the Zostera bed may involve the replacement of the associated macrobenthic community by a less diverse one. Therefore, a reduction in the area of this habitat may involve degradation in ecological quality.

Despite this, a method accounting for the relative area of each habitat has some limitations for a final integrative ES assessment. It requires implementing a monitoring program to capture the full habitat diversity that exists in the estuary, and it is therefore first necessary to have a well-founded knowledge about these habitats (Llansó et al., 2002; Diaz et al., 2004; Caeiro et al., 2005). In addition, another factor limiting the application of this method is the absence of an accurate habitat classification system. In fact, the implementation of various European Directives (Habitats Directive (Council Directive 92/43/EEC, 1992), OSPAR Convention (OSPAR, 1992), WFD) has promoted the development of various habitat classification systems (e.g., Connor et al., 1995, 2004; Davies and Moss, 1999, 2004; EUNIS, 2002), but the European scientific community has not yet reached a consensus, on either the benthic ecology terminology (namely, biotope, ecotope, assemblage, biocoenosis or natural habitats sensu Habitats Directive, etc.) (Dauvin et al., 2007b), or on the habitat definitions (Dauvin et al., 2007c).

A possibility could be the use of EU-validated EUNIS (EUNIS, 2002) and BIOMAR (Connor et al., 2004) habitat classification systems, or the development of a new system that harmonises these and other systems of marine classification (Glémarec and BellanSantini, 2005). As an example, in this work we have distinguished three different habitats: (a) mudflats covered by $Z$. noltii seagrass bed, (b) Z. noltii-Z. marina mixed meadow, and (c) bare sand. The EUNIS (EUNIS, 2002) and the BIOMAR (Connor et al., 2004) systems only recognise one type of habitat of littoral seagrass beds: " $Z$. noltii beds in littoral muddy-sand". This category may correspond to the habitat defined by us as the "mudflat covered by $Z$. noltii seagrass", but not to the $Z$. noltii-Z. marina mixed meadow. However, regarding our results, these two types of seagrass beds show very different characteristics, especially with respect to their macrobenthic assemblages. Therefore, further work is required to develop and harmonise different European habitat classification systems.

\section{Conclusions}

In general, the benthic ES has degraded in the outer part of the Eo estuary since 1990 . Nevertheless, at the present time, the human pressures on the system have apparently not exceeded the resilience of macrobenthic communities, and the outer part of the estuary consequently achieved a "Good ES" over the study period. However, the ES of the Eo estuary could be improved if there was more effective management of the bivalve aquaculture industry. This should include introducing changes in oyster culture 
practices to avoid mechanical destruction of the seagrass beds, and shellfish farming should be maintained below the ecological carrying capacity.

This study highlighted some limitations for establishing ESs in transitional water systems, which had already been recognized in other studies (e.g., Blanchet et al., 2008). Transitional systems present extreme habitat complexity, characterised by the presence of strong natural gradients that act as natural stressors affecting benthic communities in an analogous way to anthropogenic impacts. This has been termed "Estuarine Quality Paradox" (Dauvin, 2007; Elliott and Quitino, 2007). These characteristics of estuaries reduce the ability of the existing indicators and indices to distinguish between degraded versus non-degraded benthic ecological conditions. The M-AMBI index is no exception. Therefore, one of the most important challenges in the implementation of the WFD is to calibrate the methodologies for transitional water systems, with the aim of providing a reliable tool for assessing benthic ES (Dauvin, 2007; Puente et al., 2008; Blanchet et al., 2008; Borja et al., 2008).

The establishment of appropriate reference conditions is a key process within this new intercalibration exercise. The reference conditions may assume natural variability and stress in the system and separate this from the anthropogenic stress. This may be one possible way to detect anthropogenic stress, i.e., to distinguish it from the background of natural stress. As other studies are carried out in transitional water systems (Blanchet et al., 2008; Dauvin et al., 2007a; Puente et al., 2008) we suggest that these reference conditions should be habitat-specific, to properly reflect natural benthic gradients.

Therefore, it is necessary to develop an accurate habitat classification system for marine habitats, which may be a useful tool in WFD implementation for transitional water systems, as well as for the implementation of other European directives (e.g., Habitats Directive). This habitat classification system should be common to all European countries, or at least to countries belonging to the same Eco-region.

Nevertheless, from a management perspective, it would be ineffective to apply distinct management plans for each habitat. Therefore, it is necessary to generate a suitable methodology to integrate habitat level assessment in an estimation of ecological status of the entire water body, such as that proposed by Borja et al. (2005) or the methodology proposed in this contribution.

\section{Acknowledgments}

L. de Paz was supported by a doctoral grant of the Universidad de León. Parts of this work were funded through the Universidad de León Project (ULE-AG 85) and the Consejería de Agricultura y Pesca of Principado de Asturias contract. The study was also supported by FCT (Portuguese National Board of Scientific Research) through the Research Project EFICAS (POCI/MAR/61324/2004) and a Grant to J. Patrício (SFRH/BPD/26604/2006). We are grateful to E. Cimas, M. Alonso, M.A. Mayoral and especially to J.C. González Ruiz for help in collecting samples and benthic sorting, and to the staff of the Centro de Recursos Pesqueros de Castropol and R. de Paz for logistical support during field work.

\section{References}

Anonymous, 1959. Symposium on the classification of brackish waters, Venice 814th April 1958, Archivo di Oceanograpfia e Limnologia 11 (supplemento), 248 pp.

Bald, J., Borja, Á., Muxika, I., Franco, J., Valencia, V., 2005. Assessing reference conditions and physico-chemical status according to the European Water Framework Directive: a case-study from the Basque Country (Northern Spain). Marine Pollution Bulletin 50 (12), 1508-1522.

Blanchet, H., de Montaudouin, X., Lucas, A., Chardy, P., 2004. Heterogeneity of macrozoobenthic assemblages within a Zostera noltii seagrass bed: diversity, abundance, biomass and structuring factors. Estuarine, Coastal and Shelf Science 61, 111-123.

Blanchet, H., Lavesque, N., Ruellet, T., Dauvin, J.-C., Sauriau, P.G., Desroy, N., Desclaux, C., Leconte, M., Bachelet, G., Janson, A.-L., Bessineton, C., Duhamel, S. Jourde, J., Mayot, S., Simon, S., de Montaudouin, X., 2008. Use of biotic indices in semi-enclosed coastal ecosystems and transitional waters habitatsimplications for the implementation of the European Water Framework Directive. Ecological Indicators 8 (4), 360-372.

Borja, A., 2005. The European Water Framework Directive: a challenge for nearshore, coastal and continental shelf research. Continental Shelf Research 25, 1768-1783.

Borja, A., Muxika, I., 2005. Guidelines for the use of AMBI (AZTI's Marine Biotic Index) in the assessment of the benthic ecological quality. Marine Pollution Bulletin 50, 787-789.

Borja, A., Franco, J., Perez, V., 2000. A marine biotic index to the establish ecology quality of soft-bottom benthos within European estuarine coastal environments. Marine Pollution Bulletin 40, 1100-1114.

Borja, A., Muxika, I., Franco, J., 2003. The application of a marine biotic index to different impact sources affecting soft-bottom benthic communities along European coasts. Marine Pollution Bulletin 46, 835-845.

Borja, A., Franco, J., Valencia, V., Bald, J., Muxika, I., Belzune, M.J., Solaun, O., 2004a. Implementation of the European Water Framework Directive from the Basque country (northern Spain): a methodological approach. Marine Pollution Bulletin 48, 209-218.

Borja, Á., Aguirrezabalaga, F., Martínez, J., Sola, J.C., García-Arberas, L., Gorostiaga J.M., 2004b. Benthic communities, biogeography and resources management. In: Borja, Á., Collins, M. (Eds.), Oceanography and Marine Environment of the Basque Country, vol. 70. Elsevier Oceanography Series, Amsterdam, pp. 455492.

Borja, A., Bald, J., Belzunce, M.J., Franco, J., Muxika, I., Pérez, V., Solaun, O., Uriarte, A., Valencia, V., Adarraga, I., Aguirrezabalaga, F., Cruz, I., Laza, A., Marquiegui, M.A., Martínez, J., Orive, E., Ruiz, J.Ma., Sola, J.C., Trigueros, J.Ma., Manzanos, A., 2005. Red de seguimiento del estado ecológico de las aguas de transición y costeras de la Comunidad Autónoma del País Vasco. Informe de AZTI-Tecnalia para la Dirección de Aguas del Departamento de Ordenación del Territorio y Medio Ambiente, Gobierno Vasco. 14 Tomos, 718 pp.

Borja, A., Josefson, A.B., Miles, A., Muxika, I., Olsgard, F., Phillips, G., Rodríguez, J.G., Rygg, B., 2007. An approach to the intercalibration of benthic ecological status assessment in the north Atlantic ecoregion, according to the European Water Framework Directive. Marine Pollution Bulletin 55, 42-52.

Borja, A., Dauer, D., Diaz, R., Llansó, R.J., Muxika, I., Rodriguez, J.G., Schaffner, L., 2008. Assessing estuarine benthic quality conditions in Chesapeake Bay: a comparison of three indices. Ecological Indicators 8 (4), 395-403.

Boström, C., Bonsdorff, E., 1997. Community structure and spatial variation of benthic invertebrates associated with Zostera marina (L.) beds in the northern Baltic Sea. Journal of Sea Research 37, 153-166.

Buchanan, J.B., 1984. Sediment analysis. In: Holme, N.A., McIntyre, A.D. (Eds.) Methods for the Study of Marine Benthos. Blackwell Scientific Publications, Oxford, pp. 41-65.

Caeiro, S., Costa, M.H., Goovaerts, P., Martins, F., 2005. Benthic biotope index for classifying habitats in the Sado estuary: Portugal. Marine Environmental Research 60, 570-593.

Cigarría, J., Fernández, J.M., López, M., 1995. Viabilidad del cultivo de la ostra plana (Ostrea edulis L.) en la Ría del Eo (Asturias, N España). Iberus 13, 1-8.

Connor, D., Hiscock, K., Foster-Smith, R.L., Covey, R., 1995. A classification system for benthic marine biotopes. In: Eleftheriou, A., Ansell, A.D., Smith, C.J. (Eds.) Biology and Ecology of Shallow Coastal Waters. European Biology Symposium, Hersonissos, Crete (Greece), 1993. Olsen \& Olsen, Fredensborg, Denmark, pp. 55-166.

Connor, D.W., Allen, J.H., Golding, N., Howell, K.L., Lieberknecht, L.M., Northen, K.O. Reker, J.B., 2004. The marine habitat classification for Britain and Ireland Version 04.05. Joint Nature Conservation Committee Report, Peterborough, UK.

Council of the European Communities. Council Directive 92/43/EEC of 21 May 1992 on the conservation of natural habitats and wild fauna and flora. Official Journal of the European Communities Series L 1992, 206, 7-50.

Currás, A., 1990. Estudio de la fauna bentónica de la Ría del Eo (Lugo). Ph.D. Thesis Universidad de Santiago de Compostela, España, 450 pp.

Currás, A., Mora, J., 1991. Comunidades bentónicas de la Ría del Eo (Galicia-Asturias, NW España). Cahiers de Biologie Marine 32, 57-81.

Dauvin, J.-C., 2007. Paradox of estuarine quality: benthic indicators and indices, consensus or debate for the future. Marine Pollution Bulletin 55, 271-281.

Dauvin, J.-C., Ruellet, T., 2007. Polychaete/amphipod ratio revisited. Marine Pollution Bulletin 55, 215-224.

Dauvin, J.-C., Ruellet, T., Desroy, N., Janson, A.-L., 2007a. The ecological quality status of the Bay of Seine and the Seine estuary: use of biotic indices. Marine Pollution Bulletin 55, 241-257.

Dauvin, J.-C., Bellan, G., Bellan-Santini, D., 2007b. The need for clear and comparable terminology in benthic ecology. Part I: Ecological concepts. Aquatic Conservation: Marine and Freshwater Ecosystems.

Dauvin, J.-C., Bellan, G., Bellan-Santini, D., 2007c. The need for clear and comparable terminology in benthic ecology. Part II: Application of the European Directives. Aquatic Conservation: Marine and Freshwater Ecosystems.

Davies, C.E., Moss, D., 1999. EUNIS Habitat Classification. Version May 1999 European Topic Centre on Nature Protection and Diversity, Paris.

Davies, C.E., Moss, D., 2004. EUNIS habitat classification marine habitat types: revised classification and criteria. Report to the European Topic 
Centre on Nature Protection and Biodiversity/European Environment Agency, Paris.

de Paz, L., Neto, J.M., Marques, J.C., Laborda, A.J., 2008. Response of intertidal macrobenthic communities to long term human induced changes in the Eo estuary (Asturias, Spain): implications for environmental management. Marine Environmental Research, doi:10.1016/j.marenvres.2008.04.004.

Diaz, R.J., Solán, M., Valente, R.M., 2004. A review of approaches for classifying benthic habitats and evaluating habitat quality. Journal of Environmental Management 73 (3), 165-181.

EC, 2000. Establishing a framework for community action in the field of water policy. Directive 2000/60/EC of the European Parliament and of the Council. Official Journal of European Community L 327, 1-72.

Edgar, G.J., Shaw, C., Watsona, G.F., Hammond, L.S., 1994. Comparisons of species richness, size-structure and production of benthos in vegetated and unvegetated habitats in Western Port, Victoria. Journal of Experimental Marine Biology and Ecology 176, 201-226.

Elliott, M., McLusky, D.S., 2002. The need for definitions in understanding estuaries. Estuarine, Coastal and Shelf Science 55, 815-827.

Elliott, M., Quitino, V., 2007. The Estuarine Quality Paradox, Environmenta Homeostasis and the difficulty of detecting anthropogenic stress in naturally stressed areas. Marine Pollution Bulletin 54, 640-645.

Encinar, M.V., Rodríguez, G.F., 1983. Aportaciones para el conocimiento de la dinámica y la sedimentación de la ría del Eo (Asturias-Galicia, NW de España). Cuadernos del Crinas 5, $51 \mathrm{pp}$.

Escavarage, V., Ysebaert, T., Herman, P., 2004. Description of the maximal and good ecological potentials (MEP/GEP) for the benthic macrofauna for the European Water Framework Directive the Westerschelde. Report of the Koninklijke Nederlandse Academie van Wetenschappen Nederlands Instituut voor Ecologie, Yerseke, The Netherlands.

EUNIS, 2002. EUNIS Habitat Classification. European Environment Agency. <http:// eunis.eea.eu.int>

Ferreira, J.G., Nobre, A.M., Simas, T.C., Silva, M.C., Newton, A., Bricker, S.B., Wolff, W.J., Stacey, P.E., Sequeira, A., 2006. A methodology for defining homogeneous water bodies in estuaries - application to the transitional systems of the EU Water Framework Directive. Estuarine, Coastal and Shelf Science 66, 468-482.

Glémarec, M., Bellan-Santini, D., 2005. Les habitats marins. In: Bensettiti, F., Bioret F., Roland, J. (Eds.), Connaissance et gestion des habitats et des espèces d'intérêt communautaire. Habitats Côtiers. Cahiers d'habitats. Natura 2000, vol. $2+$ CDRom. MATE/MAP/MNHN, Edition La Documentation Francaise, Paris.

Grall, J., Glémarec, M., 1997. Using biotic indices to estimate macrobenthic community perturbations in the Bay of Brest. Estuarine, Coastal and Shelf Science 44, 43-53.

Hartstein, N.D., Rowden, A.A., 2004. Effect of biodeposits from mussel culture on macroinvertebrate assemblages at sites of different hydrodynamic regime. Marine Environmental Research 57, 339-357.

Llansó, R.J., Scott, L.C., Dauer, D.M., Hyland, J.L., Russell, D.E., 2002. An estuarine benthic index of biotic integrity for the Mid-Atlantic Region of the United States. I: Classification of assemblages and habitat definition. Estuaries 25 1219-1230.

McLusky, D.S., Elliott, M., 2004. The Estuarine Ecosystem-Ecology, Threats and Management. Oxford University Press. p. 214.

Mirto, S., La Rosa, T., Danovaro, R., Mazzola, A., 2000. Microbial and Meifaunal response to intensive mussel-farm bideposition in coastal sediments of the Western Mediterranean. Marine Pollution Bulletin 40, 244-252.
Muxika, I., Borja, A., Bonne, W., 2005. The suitability of the marine biotic index (AMBI) to new impact sources along European coasts. Ecological Indicators 5 19-31.

Muxika, I., Borja, A., Bald, J., 2007. Using historical data, expert judgment and multivariate analysis in assessing reference conditions and benthic ecological status, according to the European Water Framework Directive. Marine Pollution Bulletin 55, 16-29.

OSPAR, 1992. Convention for the Protection of the Marine Environment of the North-East Atlantic, 22 September 1992, Paris (published: 1993, 32 ILM 1069).

Pearson, T.H., Rosenberg, R., 1978. Macrobenthic succession in relation to organic enrichment and pollution of the marine environment. Oceanography and Marine Biology: An Annual Review 16, 229-311.

Prior, A., Miles, A.C., Sparrow, A.J., Price, N., 2004. Development of a classification scheme for the marine benthic invertebrate component, Water Framework Directive. Phase I \& II - Transitional and Coastal Waters. Environment Agency (UK), R\&D Interim Technical Report, E1-116, E1-132, 103 pp. (+appendix).

Puente, A., Juanes, J.A., García, A., Álvarez, C., Revilla, J.A., Carranza, I., 2008. Ecological assessment of soft bottom benthic communities in northern Spanish estuaries. Ecological Indicators 8 (4), 373-388.

Quintino, V., Elliott, M., Rodrigues, A.M., 2006. The derivation, performance and role of univariate and multivariate indicators of benthic change: case studies at differing spatial scales. Journal of Experimental Marine Biology and Ecology 330, 368-382.

Reiss, H., Kröncke, I., 2005. Seasonal variability of benthic indices: an approach to test the applicability of different indices for ecosystem quality assessment. Marine Pollution Bulletin 50, 1490-1499.

Rosenberg, R., Blomqvist, M., Nilsson, H.C., Cederwall, H., Dimming, A., 2004. Marine quality assessment by use of benthic species abundance distributions: a proposed new protocol within the European Union Water Framework Directive. Marine Pollution Bulletin 49, 728-739.

Salas, F., Neto, J.M., Borja, A., Marques, J.C., 2004. Evaluation of the applicability of a marine biotic index to characterize the status of estuarine ecosystems: the case of Mondego estuary (Portugal). Ecological Indicators 4, 215-225.

Simboura, N., Zenetos, A., 2002. Benthic indicators to use in ecological quality classification of Mediterranean soft bottom marine ecosystems, including a new biotic index. Mediterranean Marine Science 3/2, 77-111.

Stenton-Dozey, J.M., Jackson, L.F., Busby, J., 1999. Impact of mussel culture on macrobenthic community structure in Saldanha Bay, South Africa. Marine Pollution Bulletin 39, 357-366.

Teixeira, H., Salas, F., Pardal, M.A., Marques, J.C., 2007. Applicability of ecological evaluation tools in estuarine ecosystems: the case of the lower Mondego estuary (Portugal). Hydrobiologia 587, 101-112.

Teixeira, H., Salas, F., Borja, Á., Neto, J.M., Marques, J.C., 2008. A benthic perspective in assessing the ecological status of estuaries: the case of the Mondego estuary (Portugal). Ecological Indicators 8 (4), 404-416.

Vincent, C., Heinrich, H., Edwards, A., Nygaard, K., Haythornthwaite, J., 2002. Guidance on typology, reference conditions and classification systems for transitional and coastal waters. Produced by: CIS Working Group 2.4 (Coast), Common Implementation Strategy of the Water Framework Directive, European Commission, p. 119.

Ysebaert, T., Herman, P.M.J., Meire, P., Craeymeersch, J, Verbeek, H., Heip, C.H.R. 2003. Large-scale spatial patterns in estuaries: estuarine macrobenthic communities in the Schelde estuary, NW Europe. Estuarine, Coastal and Shelf Science 57, 335-355. 